\title{
The Social Support: A Missing Link between Safety Management Practices and Safety Behaviour of Foreign Construction Workers in Saudi Arabia
}

\author{
Bassem Alfayez \\ Department of Administrative Sciences, Community College, Al-Baha University, Al-Baha, KSA \\ Email: balfayez@hotmail.com
}

How to cite this paper: Alfayez, B. (2021). The Social Support: A Missing Link between Safety Management Practices and Safety Behaviour of Foreign Construction Workers in Saudi Arabia. Open Journal of Business and Management, 9, 990-1012. https://doi.org/10.4236/ojbm.2021.93053

Received: December 28, 2020

Accepted: April 4, 2021

Published: April 7, 2021

Copyright ( 2021 by author(s) and Scientific Research Publishing Inc. This work is licensed under the Creative Commons Attribution International License (CC BY 4.0).

http://creativecommons.org/licenses/by/4.0/ (c) (i) Open Access

\begin{abstract}
Organizational injuries and accident has become a major issue in many countries especially among foreign workers in the construction sector. This paper aims to examine the safety behavior of foreign workers in the Jeddah construction industry by examining the direct relationships between safety management practices (priority of safety, safety communication, and work pressure) on safety compliance and safety participative behavior. Also, social support was tested as a moderator on these relationships. Partial Least Square Techniques 3.0 (PLS) approach was used to test the hypotheses. The finding showed that the priority of safety and safety communication predicts both safety compliance and participative behavior in this study. While the relationships between work pressure and safety compliance and participation are not significant. Results for the moderation effects of social support revealed that the relationship between safety communication and work pressure on safety participation was influenced by social support. The finding in this study provides empirical support of social support as a moderator and contributes to the role of social exchange theory and can assist construction practitioners in Saudi Arabia on how to improve construction workers safety behavior. Finally, this study discusses theoretical and practical implications, as well as recommendations for future research.
\end{abstract}

\section{Keywords}

Safety Behaviour, Work Pressure, Social Support, Foreign Workers, Construction Industry 


\section{Introduction}

Every year, hundreds of thousands of employees are injured at work, while billions of dollars are consumed as a result of medical costs, disability payments, increased insurance premiums and decreased productivity (Occupational Safety \& Health Administration, 2015; Xia, Xie, Griffin, Ye, \& Yuan, 2020). For example, the financial cost of such safety-related incidents is estimated to be approximately US $\$ 1$ billion per week (Occupational Safety \& Health Administration, 2015). Such occupational accidents are therefore associated with huge economic and social costs. In addition to those costs, accidents result in an increase in the time taken to complete a project (Demirkesen, 2020).

Similarly high rate of fatalities and injuries has been reported in the Middle East, where 19,000 deaths and more than 14 million work-related injuries are recorded annually (ILO, 2012). The issue of occupational safety in Saudi Arabia continues to represent a major challenge. The statistics presented by the General Organization for Social Insurance (GOSI, 2012) show that between 2004 and 2010 , the number of serious injuries totalled 261,076 annually, which is equivalent to 3413.9 injuries per 100,000 employees on average. The total number of injuries that resulted in death was 2176, indicating an average rate of 28.3 deaths per 100,000 workers per annum (Liu, Yang, \& Mei, 2020). A comparative study of cases of work-related injury and death worldwide using the available statistical evidence suggests that Saudi Arabia recorded the highest number of major injuries (3117) as well as 28 cases of death out of every 100,000 workers injured in 2008 (Alasamri, Chrisp, \& Bowles, 2012).

Construction activities in Saudi Arabia have rapidly increased over the past twenty years and construction firms from around the world have taken part in various development projects (Al-Haadir \& Panuwatwanich, 2011). According to the report on the Ninth Development Plan published by the Ministry of Economy and Planning (MEP), the annual growth rate of the construction sector is 7.2 percent, which can be compared with the growth rate of 4.7 percent reported in the previous plan, and it is expected to reach approximately 7.8 percent towards the end of 2014 (MEP, 2014). Foreign workers are vitally important to the Saudi Arabian economy due to the high volume of economic activities conducted within the country that are largely dependent on such workers (Al-Haadir \& Panuwatwanich, 2011). In 2013, the Saudi Ministry of Labour and Social Development (MLSD) estimated that over eight million workers employed in the country were foreign born, with 3.6 million (45\%) of them working in the construction sector (MLSD, 2013).

Numerous empirical studies have found that foreign workers face many occupational safety issues and social challenges when trying to adapt to their host countries. For example, Rautiainen (2012) noted that homesickness is a major source of stress for foreign workers, especially those who are married and living away from their families. As a result, this segment of workers requires a long 
time to adapt to a new environment. Rautiainen (2012) added that if these workers continue to feel homesick and do not have the opportunity to engage in social interactions/activities.

In the safety management literature, there is a call to incorporate moderating variables to shed the light on the influence of organizational factors on safety performance (e.g., Foster \& Nichols, 2015). This is crucial due to the fact that there are inconsistent results reported in the literature (Vinodkumar \& Bhasi, 2010). More importantly, scholars such as Foster and Nichols (2015) asserted that the moderating role of contextual factors is understudied in the domain of safety research. Drawing on these assertions, social support was incorporated as a moderator. Social support is defined as the Social support is defined as social exchange or relationship that helps the workers with actual guidelines and assistance or with a feeling of affiliation or attachment to an individual or group that is perceived as loving or caring (Hobfoll \& Stokes, 1988). Hence, the paper objective is to examine how safety management practices (Work Pressure, Priority of Safety and Safety Communication and Feedback) predict safety performance among foreign construction workers in Saudi Arabia. To further elicit a better understanding of the aforesaid relationship, social support is integrated into the model as the moderating factor.

\section{Literature Review}

\subsection{Safety Performance}

Safety compliance is defined as adhering to safety procedures and carrying out work in a safe manner (Neal et al., 2000; Shi, 2020). Borman and Motowidlo (1993) stated that safety compliance is actually related to task performance. Al-Haadir et al. (2013) explained safety compliance (task performance) to be the core safety activities that need to be carried out by individuals in order to maintain workplace safety, such as wearing personal protective equipment. Compliance with rules and regulations is one of the imperative features of safety performance. The term "safety compliance" refers to the core behavior workers need to perform to maintain workplace safety. Such behavior includes maintaining the standard of work procedures and wearing personal protective equipment (Neal \& Griffin, 2006). Moreover, safety compliance serves to make people at work more aware of rules and regulations concerning safety measures and their implementation (Neal \& Griffin, 2006). Similarly, Leung et al. (2015) described safety compliance as behavior aimed at meeting the minimum safety criteria, such as following safety procedures in the workplace. Neal et al. (2000) defined safety compliance as a situation in which workers comply with safety procedures and work in a safe manner. According to Inness, Turner, Barling and Stride (2010), safety compliance comprises task performance and core safety-related activities, since it is compulsory for workers to have at least minimum safety in their workplace.

Based on the above definitions, and in the context of the present study, safety 
compliance is here defined as the foreign workers' compliance with onsite safety activities, including taking precautionary measures, wearing protective equipment and following the stipulated safety instructions. Compliance with safety-related rules and regulations is important for foreign workers, since it is not just their safety at stake but also the safety of their co-workers', which is a priority for construction companies. Foreign workers need to adjust themselves and behave in a safe manner in order to maintain safety standards by following safety procedures and taking all the required precautions.

Safety participation is defined as employees' voluntary behaviors that contribute to safety (Neal et al., 2000). It includes behaviors that extend beyond an employee's formal role (Jiang et al., 2010). Safety participation requires co-workers to be helped to enhance and comply with safety programmes in the workplace as well as to take the initiative and expend effort to ensure safety in the workplace (Neal et al., 2000). Safety participation is a similar concept to organisational citizenship behaviors (OCBs), which include voluntary behaviors that are favourable to the organisation (Hofmann, Morgeson, \& Gerras, 2003). Safety participation is important in terms of understanding safety behavior. It comprises a variety of activities, including helping with safety-related issues, active involvement in voluntary safety activities and attending safety meetings (Broadbent, 2004; Lu \& Yang, 2011; Neal \& Griffin, 2006). In other words, safety participation implies that the behavior of workers does not directly influence other workers' safety, but rather educates the public about the importance of creating an environment that is conducive to safety (Neal \& Griffin, 2006; Neal et al., 2000). Al-Haadir, Panuwatwanich and Stewart (2010) similarly stated that safety participation behaviors do not contribute to workplace safety directly, but instead help to promote an environment that supports safety (Neal \& Griffin, 2006).

\subsection{Safety Management Practices}

During the past 50 years, greater attention has been given in safety research in comprehending how safety management practices and other similar organizational factors influence organizational safety outcomes. Hale and Hovden (1998) indeed, refer this as the third age of safety. Safety management practices can be defined as organization's procedures and policies for safeguarding the safety, health and well-being of workers in the organization (Barlow \& Iverson, 2005). Vinodkumar and Bhas (2010: p. 283) defined safety management as the policies, strategies, procedures and activities implemented or followed by the management of an organization targeting safety of their employees. Even though various empirical studies (e.g., Ali, Abdullah, \& Subramaniam, 2009; Mearns, Whitaker, \& Flin, 2003; Vinodkumar \& Bhasi, 2010; Vredenburgh, 2002) have provided empirical support for the role of individual attributes, leadership style, and situational factors in improving organizational safety, theoretical model developed by Vinodkumar and Bhasi (2010) proposed that safety management practices are 
deemed more crucial in explaining safety performance level in organizations. Specifically, the dimensions of safety management practices discussed in this paper comprised of Work Pressure, Priority of Safety and Safety Communication and Feedback.

\subsubsection{Priority of Safety and Safety Behaviour}

Priority of safety is a vital factor that determines the success of the safety climate (Bosak et al., 2013). The priority of safety is defined as the degree to which workers perceive safety to be a top priority on the part of the management (Bosak et al., 2013). It has been recognised that the greater the priority assigned to safety within the organisation, the more workers are motivated to take greater ownership and accountability for safety, which induces them to behave in a safe manner (Bosak et al., 2013).

Safe working implies that employees need to slow down and take extra care (Naveh, Katz-Navon, \& Stern, 2006). A high safety priority within an organisation means that safety is considered to be an important issue that must be given precedence regardless of other competing demands, for example, work speed and productivity (Fleming \& Lardner, 1999). The safety priority is an important dimension of the safety climate and it is linked to employee expectations concerning the balance maintained between work pressures, time, speed and workload for a production output and related to various safety outcomes (Fleming \& Lardner, 1999).

In summary, the literature on the priority of safety generally indicates a positive association between the safety priority and workers' safety behaviors (Vinodkumar \& Bhasi, 2009). Therefore, it is hypothesised that:

H1a: There is a significant positive relationship between the priority of safety and safety compliance.

H1b: There is a significant positive relationship between the priority of safety and safety participation.

\subsubsection{Safety Communication and Feedback and Safety Behaviour}

The significance of safety communication and feedback and its association with workplace safety has been recognized across several industries and countries (Hon, Chan, \& Wong, 2010; Keffane \& Delhomme, 2013). Safety communication and feedback is defined as the provision of information and data on the safety level of an organization to identify the degrees of risk that result in accidents in the workplace (Bentley \& Haslam, 2001). Literature (for example Zohar, 1980), reported safety communication and feedback is related with organizational safety practices safety participation (Neal et al., 2000) and safety compliance (Vinodkumar \& Bhasi, 2010; Berhan, 2020; Liu \& Liao, 2019; Usukhbayar \& Choi, 2020; Liu, Tang, Liao, \& Xu, 2020; Ali, Aziz, Pham, Babalola, \& Usman, 2020). Most importantly, this factor is also reported to lower the level of injuries and accidents in organizations (Ali et al., 2009). Safety communication and feedback can thus be considered as a significant construct in understanding 
nurses' safety and it may serve as a leading safety indicator of accident and injuries (Hofmann \& Mark, 2006).

In the safety literature, it has been acknowledged that effective safety communication and feedback between employees and management are among the main characteristics that differentiate between organizations with high injuries and accident from those with low injuries (Zohar, 1980). Vinodkumar and Bhasi (2010) opined that "regular communication about safety issues between managements, supervisors and workforce is an effective management practice to improve safety in workplace" (p. 2084). Hofmann and Morgeson (1999) listed communication as among the top 10 safety management practices, which helps to improve safety performance in the workplace. Similarly, a number of studies have also found that safety communication and feedback is positively related to safety performance (Vinodkumar \& Bhasi, 2010). Taken together, it is evident that positive perceptions of safety communication and feedback are important in ensuring employees' safety compliance and participation. Therefore, we hypothesized that:

Hypothesis 2a: Safety communication and feedback is positively related to safety compliance.

Hypothesis 2b: Safety communication and feedback is positively related to safety participation.

\subsubsection{Work Pressure and Safety Behaviour}

Achieving a balance between workload, time and space is crucial if employees are to perform their work safely (Seo, 2005). Basically put, work pressure is an important dimension of the safety climate that has been reported to impact various employee safety outcomes, including unsafe behavior (Bronkhorst, 2015). Work pressure has been defined as the "degree to which employees feel under pressure to complete work, the amount of time to there is to plan and carry out work and the balance of workload" (Glendon \& Stanton, 2000: p. 202). Workers who are subjected to a high level of work pressure are less likely to use personal protective equipment (Bronkhorst, 2015). Employees' psychological stress generally appreciates due to work pressure, which eventually increases the chances of employees becoming involved in workplace accidents and injuries. When employees are working under a condition of pressure or work overload, they may ignore safe precautions, rules and regulations in order to complete their work as quickly as possible (Pordanjani \& Ebrahimi, 2015).

Previous studies have found work pressure to have a significant influence on safety behavior as well as occupational accidents (e.g. Pordanjani \& Ebrahimi, 2015; Sadullah \& Kanten, 2009). For example, Bronkhorst (2015) conducted a study on 6230 health care employees of 52 organisations and found that work pressure has a significantly negative influence on physical safety behavior. Therefore, we hypothesized that:

Hypothesis $3 \mathrm{a}$ : work pressure is negatively related to safety compliance.

Hypothesis 3 b: work pressure is negatively related to safety participation. 


\section{Methodology}

\subsection{Sample and Data Collection Procedure}

The research methodology employed in this study was quantitative research method using questionnaires to test the conceptual model. The population in this study comprises foreign construction workers (individual workers who are at risk of workplace injuries and accidents, including electricians, iron workers, drillers, plumbers, painters, equipment operators and other relevant onsite workers). To achieve the research objective, data was collected from Al Muhaidib Construction Company which included 8738 workers as of October 2015. Al-Muhaidib Contracting Company one of the largest construction company in Saudi Arabia it was established in 1398 (H), 1977 (G) and is fully Saudi owned. The company is a subsidiary of Abdul Kadir Al-Muhaidib\& Sons Group. Since its inception, Al-Muhaidib Contracting Company has been engaged in the construction of residential and commercial buildings, office buildings, hospitals, schools, sewer lines, water lines, wastewater treatment plants, water purification and desalination plants. The company is a registered contractor with Saudi Aramco, SCECO and government departments. Established as a leading turnkey construction firm of recognized capabilities and accomplishments, Al Muhaidib Contracting owes its steady growth succeeding with a multitude of Infrastructure projects conducting long term business relations at international levels. Pioneering today's competitive market, Al Muhaidib Infrastructure has broadened its horizons to an independent division anchoring its substantial investments in highly specialized equipments and unique operating systems with its steadfast commitment towards remarkable excellence optimally exceeding client expectations.

For a study population of 9000, Krejcie and Morgan (1970) suggested that a sample size of 368 workers would be adequate. In order to comprehend the sample size determination as suggested by Krejcie and Morgan (1970), a state-of-the-art technique was incorporated into this study to estimate the minimum sample size required. The $\mathrm{G}^{*}$ Power analysis was used to compute the statistical power analyses for various different statistical tests. It can also be used to compute effect sizes and display the graphical results of power analyses (Faul, Erdfelder, Lang, \& Buchner, 2007). Hence, the present study distributed 368.

The questionnaires were distributed and administered personally by the researcher. The core motivation for distributing the questionnaires in this manner was to enable the researcher to explain the purpose and the benefits of the study as well as to encourage the participants to provide honest answers (Sekaran \& Bougie, 2003).

\subsection{Data Analysis Technique}

The study employed Structural Equation Modeling via Partial Least Square (PLS SEM) SmartPLS 3.2 software (Ringle et al., 2015) to compute both the measurement and structural models (Anderson \& Gerbing, 1988). The rationales for us- 
ing SmartPLS are because PLS path models are estimated with a small sample and with non-normal data (Haenlein \& Kaplan, 2004). Further, PLS has the likelihood of providing accurate computations of moderating effect because its accounts for error (Helm, Eggert, \& Garnefeld, 2010). The two-step technique as recommended by Anderson and Gerbing (1988) and suggestion of Hair et al. (2011) were used. In addition, the bootstrapping technique (5000 resample) was also used to ascertain the significance levels of the path coefficient.

\subsection{Measures}

To measure the constructs, items developed by the previous study were adopted in this study. Four items were used to measure the priority of safety from Cox and Cheyne (2000). Some examples include: "Management clearly considers the safety of foreign workers of great importance" and "I believe that safety issues are not assigned a high priority". The internal consistency value of these items was 0.722 .

Five items were to measure safety communication and feedback were adapted from Cox and Cheyne (2000). Some examples include: "Safety information is always brought to my attention by the management" and "There is good communication here about safety issues which affect me". The internal consistency value of the items was 0.734 .

Six items were adapted from Glendon and Litherland (2001) in order to measure work pressure, A five-point Likert scale that ranged from " 1 " or "strongly disagree" to " 5 " or "strongly agree" was utilised to measure the safety climate items. Some examples include: "There are enough workers to carry out the required work" and "Time schedules for completing work projects are realistic". The internal consistency value of the items was 0.89 .

The current study used social support scaled by measuring the supervisor, co-worker and family support, as recommended by Lee and Hong (2005). Some examples of the items used to measure supervisor support include: "How much does your supervisor recognise and value your job?" and "How much support do you receive from your supervisor?”. In the study by Fujiwara et al. (2003), the internal consistency of the Cronbach's alpha value was found to be 0.87 .

A total of four items were used to measure workers' compliance. Some examples of the items include: "I use necessary safety equipment to do my job" and "I follow correct safety rules and procedures while carrying out my job". These items were adapted from Vinodkumar and Bhasi (2010) and their internal consistency value was 0.66 .

A total of four items were used to measure safety participation. Some examples of the items include: "I voluntarily carry out tasks or activities that help to improve workplace safety" and "I always point out to the management if any safety-related matters are noticed in my company". These items were adapted from Vinodkumar and Bhasi (2010) and their internal consistency value was 0.66 . 


\subsection{Translation of the Questionnaire}

The original version of the questionnaire was prepared in English. As previously stated, the population of the present study is foreign workers. Accordingly, the questionnaire was translated into three main languages, namely Arabic, Urdu (Pakistan) and Hindi (Indian). The questionnaire was translated using the back-translation method to ensure that an equivalence of measures was achieved in all the languages spoken by the foreign workers (Brislin, 1970). The translation of the questionnaire was performed by the Huna Khidma Translations Agency. This agency's translation service is approved and accepted by the Saudi Arabian Government. Basically, the translation of the questionnaire involved two steps. First, a comparison between the original version of the English questionnaire and the back-translated English version of the questionnaire was performed, which suggested that no major rewording was needed for any items. Second, to ensure that the original meanings were maintained after the translation was performed, the researcher held detailed discussions with the Huna Khidma Translations Agency.

In the present study, prior to distributing the questionnaire in the pilot study phase, it was given to experts in safety who work in the safety department of the Al Muhaidib Contraction Company to check for any necessary corrections and observations. These experts verified the wording as well as the content of the questionnaire.

\section{Results and Analysis}

\subsection{Demographic Profile of the Respondents}

The demographic profile of the respondents indicates that $53.5 \%(\mathrm{n}=151)$ of them have a certificate or lower in terms of their education level. However, $48 \%$ of respondents have educational qualifications that differ from those listed, including specific technical qualifications for use on a construction site, for example, the Technical Programme for Construction Equipment Operators (crane operator, forklift driver, etc.). Meanwhile, 55.7\% $(n=157)$ of respondents are aged between 21 and 30 years, which indicates that construction companies are hiring young workers despite the majority of them being only lowly qualified. This might be due to the heavy nature of the work involved in the construction. With regards to gender, all the respondents are male $100 \%(\mathrm{n}=282)$, which is likely due to the fact that only men are employed on constructions site in Saudi Arabia.

The results also show that the majority of respondents were from Pakistan ( $39.4 \%, n=111)$, since the Pakistani workers represented the majority of foreign workers employed on the construction site. Meanwhile, only $1.4 \%(n=4)$ of workers were from the Philippines and they thus represented the minority of foreign workers. The demographic results also show that despite the majority of respondents $(67.7 \%, \mathrm{n}=191)$ having worked abroad for between one and five years and the majority of them $(88.7 \%, \mathrm{n}=250)$ having also attended occupa- 
tional safety training, the majority of respondents $(56 \%, \mathrm{n}=158)$ still reported having had an occupational accident (see Table 1).

Table 1. Frequencies of demographic respondents.

\begin{tabular}{|c|c|c|}
\hline Demographic attributes & Frequency & $\%$ \\
\hline \multicolumn{3}{|l|}{ Education level } \\
\hline Certificate or lower & 151 & 53.5 \\
\hline Diploma & 57 & 20.2 \\
\hline Bachelor degree & 26 & 9.2 \\
\hline Others & 48 & 17.0 \\
\hline Total & 282 & 100 \\
\hline \multicolumn{3}{|l|}{ Gender } \\
\hline Male & 282 & 100 \\
\hline Female & 0 & 0 \\
\hline Total & 282 & 100 \\
\hline Country of origin & & 100 \\
\hline India & 96 & 34.0 \\
\hline Pakistan & 111 & 39.4 \\
\hline Egypt & 36 & 12.8 \\
\hline Yemen & 24 & 8.5 \\
\hline Philippines & 4 & 1.4 \\
\hline Syria & 11 & 3.9 \\
\hline Total & 282 & 100 \\
\hline \multicolumn{3}{|l|}{ Age } \\
\hline $21-30$ & 157 & 55.7 \\
\hline $31-40$ & 98 & 34.8 \\
\hline $41-50$ & 25 & 8.9 \\
\hline More than 50 & 2 & 0.7 \\
\hline Total & 282 & 100 \\
\hline \multicolumn{3}{|l|}{ Experience (in years) } \\
\hline $1-5$ & 126 & 44.7 \\
\hline $6-10$ & 122 & 43.3 \\
\hline $11-15$ & 25 & 8.9 \\
\hline $16-20$ & 9 & 3.2 \\
\hline Total & 282 & 100 \\
\hline \multicolumn{3}{|c|}{ Experience Working Abroad (in years) } \\
\hline $1-5$ & 191 & 67.7 \\
\hline $6-10$ & 83 & 29.4 \\
\hline $11-15$ & 7 & 2.5 \\
\hline $16-20$ & 1 & 0.4 \\
\hline Total & 282 & 100 \\
\hline
\end{tabular}




\subsection{Common Method Variance}

To minimize the potential effect of common method variance (CMV) in our study, we used both procedural and statistical remedies as suggested by Podsakoff et al. (2003). Firstly, expert opinion was received through content validity of the items to avoid vague concepts in the questionnaire (Podsakoff et al., 2003). Similarly, we used reverse worded questions and allowed the respondent's anonymity in answering the questionnaire (Podsakoff et al., 2003). Additionally, we assured the respondents that their answers will be kept confidential and they should answer the questions as honestly as possible as there are no right or wrong answers (Podsakoff et al., 2003). Secondly, Harman's single-factor test was conducted using SPSS, un-rotated factor analysis with forty seven items of all the constructs. The finding shows that no single factor accounted for more than $50 \%$ of the variance.

\subsection{Measurement Model Evaluation}

To evaluate the measurement model in this paper, two types of validity were assessed, namely convergent validity and discriminant validity. Convergent validity is determined by examining the composite reliability, and average variance extracted (AVE) (Hair et al., 2011). As depicted in Table 1, Composite reliability (CR), Cronbach's Alpha andrho_A of all the constructs were higher than 0.7 and average variance extracted (AVE) was above 0.5 , as recommended by Hair et al. (2011) (refer to Table 2).

The HTMT ratio was examined as this criterion is regarded to be a more reliable criterion for evaluating discriminant validity than the Fornell-Larcker criterion (Henseler, Ringle, \& Sarstedt, 2015). The HTMT criterion in this study shows that discriminant validity is achieved which is within the conventional yardstick of 0.85 (Henseler et al., 2015) as shown in Table 3. Therefore, both the two types of validity in this study were achieved.

Table 2. Reliability and average variance extracted.

\begin{tabular}{ccccc}
\hline Constructs & $\begin{array}{c}\text { Cronbach's } \\
\text { Alpha }\end{array}$ & rho_A & $\begin{array}{c}\text { Composite } \\
\text { Reliability }\end{array}$ & $\begin{array}{c}\text { Average Variance } \\
\text { Extracted (AVE) }\end{array}$ \\
\hline $\begin{array}{c}\text { Priority } \\
\text { of Safety }\end{array}$ & 0.796 & 0.805 & 0.881 & 0.713 \\
$\begin{array}{c}\text { Safety } \\
\text { Communication }\end{array}$ & 0.837 & 0.835 & 0.886 & 0.611 \\
$\begin{array}{c}\text { Safety } \\
\text { Compliance } \\
\text { Safety } \\
\text { Participation } \\
\text { Social } \\
\text { Support }\end{array}$ & 0.838 & 0.860 & 0.889 & 0.668 \\
Work & 0.808 & 0.809 & 0.874 & 0.635 \\
Pressure & 0.925 & 0.930 & 0.936 & 0.573 \\
\hline
\end{tabular}


Table 3. Discriminate validity Heterotrait-Monotrait ratio (HTMT).

\begin{tabular}{cccccc}
\hline Constructs & $\begin{array}{c}\text { Priority } \\
\text { of Safety }\end{array}$ & $\begin{array}{c}\text { Safety } \\
\text { Communication }\end{array}$ & $\begin{array}{c}\text { Safety } \\
\text { Compliance }\end{array}$ & $\begin{array}{c}\text { Safety } \\
\text { Participation }\end{array}$ & $\begin{array}{c}\text { Social } \\
\text { Support }\end{array}$ \\
\hline $\begin{array}{c}\text { Priority } \\
\text { of Safety } \\
\text { Safety } \\
\text { Communication }\end{array}$ & 0.595 & & & & \\
$\quad \begin{array}{c}\text { Safety } \\
\text { Compliance } \\
\text { Safety }\end{array}$ & 0.388 & 0.429 & & & \\
$\begin{array}{c}\text { Participation } \\
\text { Social }\end{array}$ & 0.416 & 0.471 & 0.896 & & \\
Support & 0.505 & 0.449 & 0.717 & 0.615 & \\
Work & 0.569 & 0.596 & 0.465 & 0.392 & 0.661 \\
Pressure & 0 & & & & \\
\hline
\end{tabular}

\subsection{Structural Model Evaluation}

Since the measurement model above is achieved in term of reliability and validity, we evaluated the structural model to assess the hypothesized relationships among the variable in this study (Hair et al., 2011). Before we evaluate the hypothesized relationships among the variables, we used the recent suggestion of Henseler, Hubona and Ray (2016) and apply the standardized root mean square residual (SRMR) to evaluate the appropriateness of the model fit. SRMR value of zero indicates a perfect model fit and generally, an SRMR value less than 0.08 is suggested to achieve adequate PLS path models. In our study, the SRMR $=0.075$ was observed, demonstrating an adequate model fit (Henseler et al., 2016). As presented in Figure 1 and Figure 2, we evaluated the standardized beta values and the t-values (Hair et al., 2011). The t-values were obtained using bootstrapping procedure with 5000 resamples. In addition, we also calculated the predictive relevance $(\mathrm{Q} 2)$ of the model and the effect sizes of each predictor on the dependent variables (f2) (Hair et al., 2011). Additionally, in testing the relationships of the structural model, the significance level was set at $p<0.001, p<0.05$ (1-tailed) (Hair et al., 2011).

\section{Structural Model Assessment Main Effect}

We examined the hypothesized paths using Smart PLS 3.2 and the findings on the hypothesized direct relationships are depicted in Table 4 . The results indicated that Priority of Safety $(\beta=0.133 ; \mathrm{t}=2.166 ; p<0.05)$, Safety Communication $(\beta=0.156 ; \mathrm{t}=3.678 ; p<0.01)$ and Work Pressure $(\beta=0.291 ; \mathrm{t}=4.250 ; p<$ 0.01 ) have positive effects on safety compliance. Therefore, H1a, H2a, and H3a are supported.

The results also indicate that Priority of Safety $(\beta=0.155 ; \mathrm{t}=2.141 ; p<0.05)$, Safety Communication $(\beta=0.244 ; \mathrm{t}=3.678 ; p<0.01)$ and Work Pressure $(\beta=$ $0.136 ; \mathrm{t}=1.843 ; p<0.01$ ) have positive effects on safety participation. Therefore, $\mathrm{H} 1 \mathrm{~b}, \mathrm{H} 2 \mathrm{~b}$, and $\mathrm{H} 3 \mathrm{~b}$ are supported. 


\section{Structural Model Assessment with Interaction Effect}

With regard to the moderating effects of social support, the study applied product-indicator approach to create the interactions which was calculated in SmartPLS 3.2 (Hair et al., 2011) as presented in Figure 1 the results found the moderating effect of social support on the relationship between safety communication and safety participation. To aid the interpretation of the moderating effects, we plotted simple slope in Figure 2. It can be seen from Figure 2 that workers of different level of social support did not differ much in safety participation under conditions of low work pressure, but differences were noted under conditions of high work pressure (Figure 3).

Table 4. Direct relationships.

\begin{tabular}{ccccc}
\hline Relationships & Beta Value & T Value & P Values & Decision \\
\hline Priority of Safety $->$ Safety Compliance & 0.133 & 2.166 & $0.015^{*}$ & Supported \\
Priority of Safety $->$ Safety Participation & 0.155 & 2.141 & $0.016^{*}$ & Supported \\
Safety Communication $->$ Safety Compliance & 0.156 & 2.645 & $0.004^{* *}$ & Supported \\
Safety Communication $->$ Safety Participation & 0.244 & 3.678 & $0.000^{\star *}$ & Supported \\
Work Pressure $->$ Safety Compliance & 0.291 & 4.250 & 0.000 & Not-Supported \\
Work Pressure $->$ Safety Participation & 0.136 & 1.843 & 0.033 & Not-Supported \\
\hline
\end{tabular}

Note: ${ }^{*}$ Significant at 0.01 (1-tailed), ${ }^{\star}$ Significant at 0.05 (1-tailed).

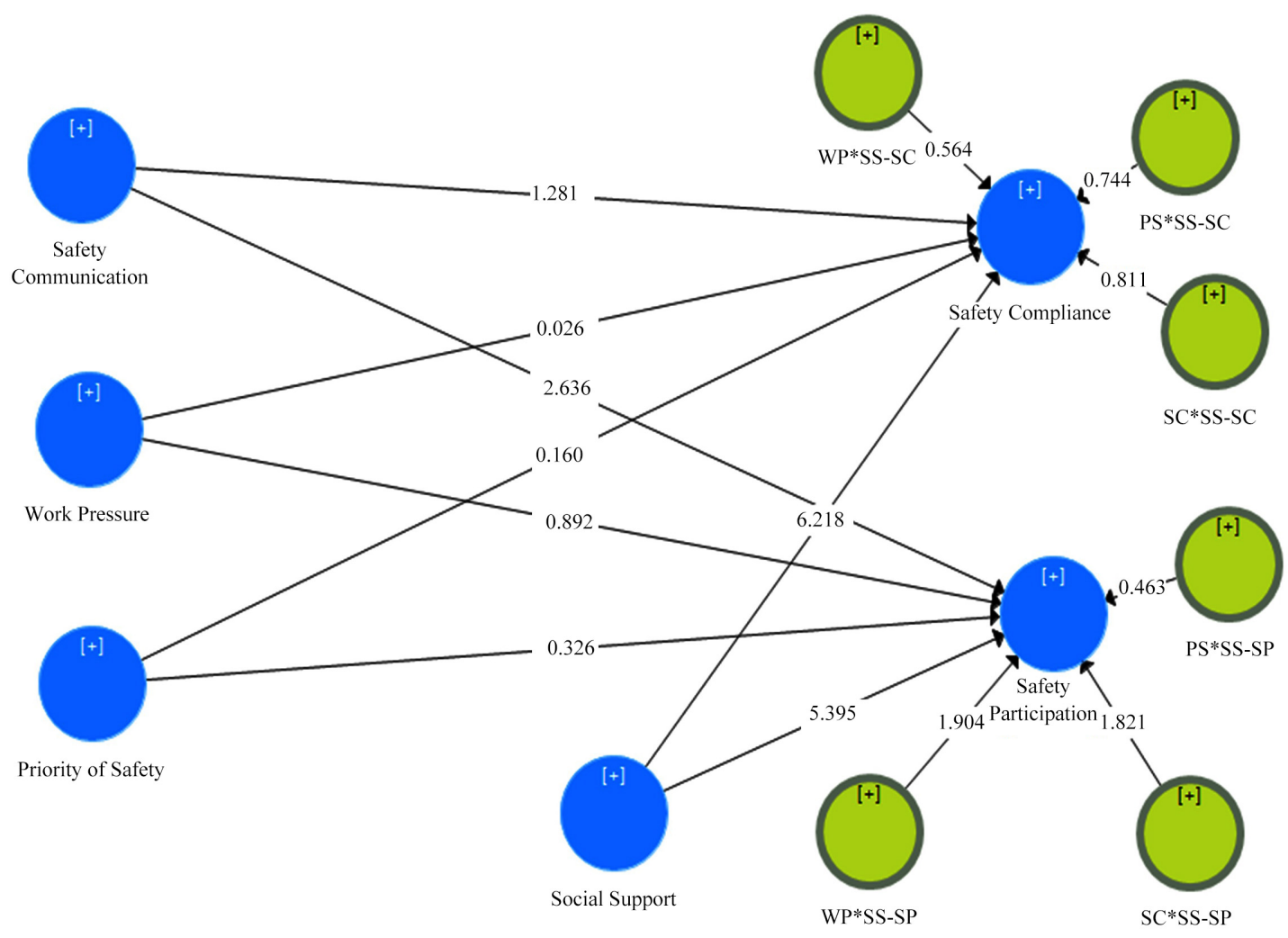

Figure 1. Structural model. 


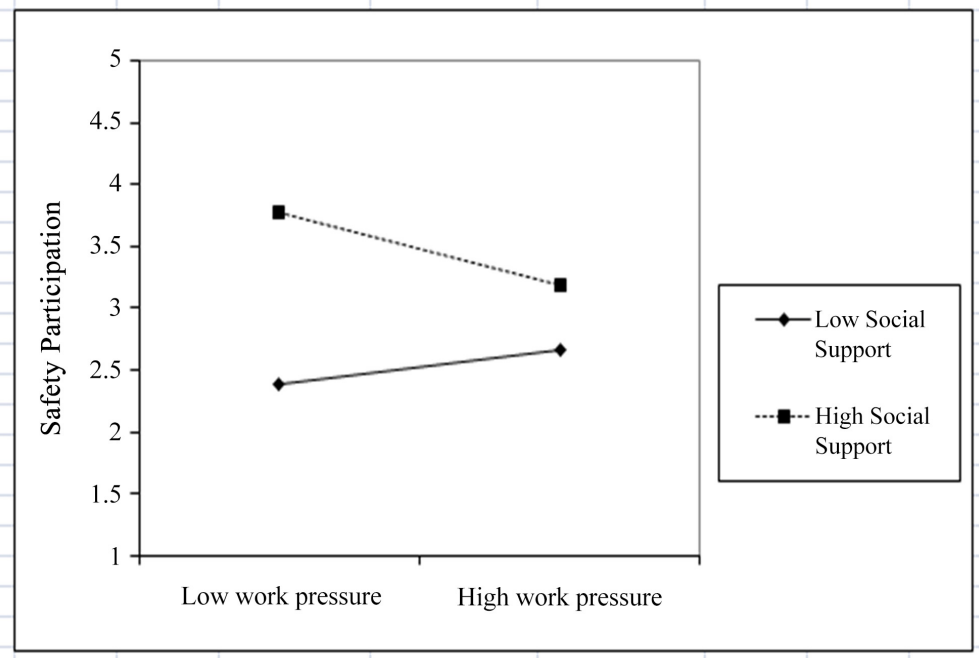

Figure 2. Interaction effect of work pressure and social support on Safety participation.

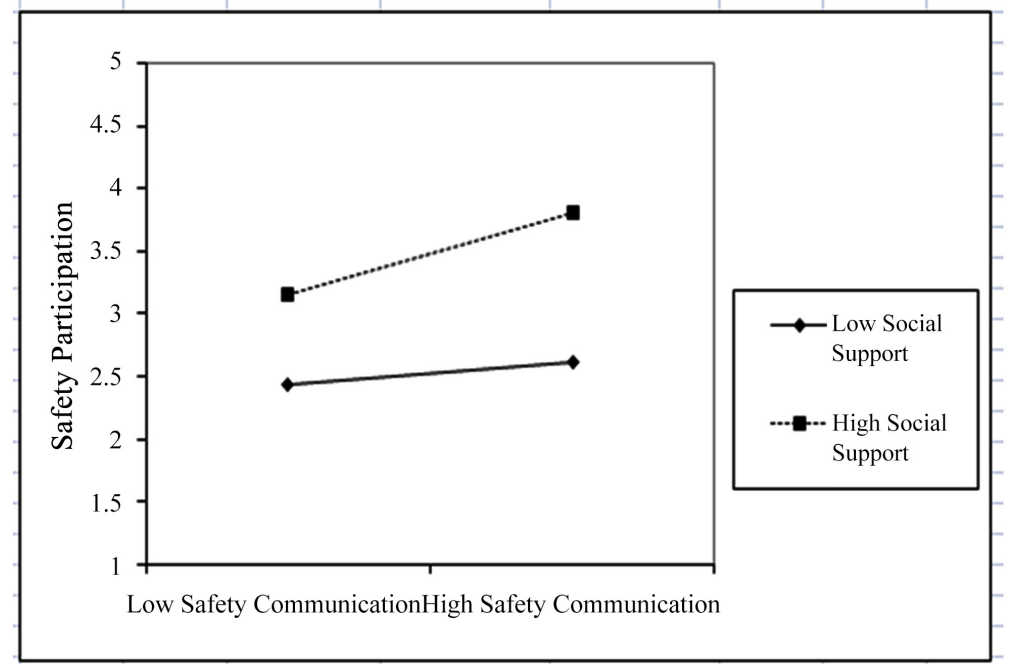

Figure 3. Interaction effect of safety communication and social support on Safety participation.

\section{Discussion}

The findings of this study demonstrated significant relationship between the priority given to safety and construction workers' safety-related behavior (safety compliance and safety participation) The finding from this study is consistent with the previous studies (e.g., Hong, 2015; Rundmo \& Moen, 2007). For example, Katz-Navon et al. (2005) found significant effect on direct relation between safety priority and safety performance. Zohar and Erev (2007) stated that an organisation that makes safety procedures contingent on production pressures will affect workers' perception of the actual priority assigned to safety, which will consequently affect their safety-related behavior.

The findings of this study demonstrated a significant positive relationship 
between safety-related communication and construction foreign workers safety participation. In other words, if management communicates safety to the foreign workers, the workers will exchange in participation in safety activities. The finding from this study is consistent with the previous studies (e.g., Arboleda et al., 2003; Bentley \& Haslam, 2001; Conchie et al., 2011; Vredenburgh, 2002). For example, Cigularov et al. (2010) conducted a study of the construction industry in the US, and found that there is a significant positive relationship between safety communication and safety participation. Such a significant relationship between safety communication and safety participation could be attributed to a high level of communication between management and workers (Hardison et al., 2014). Fleming and Lardner (1999) argued that the quality and frequency of safety-related communication between managers and employees is likely to influence the safety behavior of construction workers. In the context of this study, the management of the Al Muhaidib construction company assigns a specialist safety team to each construction project in order to closely communicate with foreign workers and encourage them to participate in the company's safety programme.

This study hypothesised that there exists a significant negative relationship between work pressure and construction foreign workers' safety behavior (safety compliance and safety participation). Such a hypothesis was not in fact supported by the findings of this study, which instead demonstrated a non-significant relationship between work-related pressure and construction foreign workers' safety behavior (see Table 4). The finding from this study is consistent with the previous studies (e.g., Ghasemi et al., 2017; Mohamed, 2002). For example, Mohamed (2002) investigated the association between ten dimensions of safety climate and safety performance and that between safety climate and safety behavior in 19 construction sites in the South Queensland, Australia and found that work pressure is not directly significant with the safety behavior. The author claimed that non-significant relationship could be due to the psychological aspects of working under pressure and perceiving the conflicting safety and production requirements. The possible reason for the non-significant relationship between work pressure and safety behavior identified in this study may be attributed to the fact that "working under pressure is the norm in the construction industry" (Mohamed, 2002: p. 381).

As hypothesised in this study, with regards to the potential moderating effect of social support, the results reveal that social support significantly moderated the relationships between 1) work pressure and safety compliance, 2) safety communication and safety participation. The findings of this study are therefore consistent with the conclusions of previous studies that found social support to serve as a moderator (e.g., Jamal, 2013; Martz et al., 2010; Wickramasinghe, 2012). For example, Abualrub, Omari, Al Rub and Fawzi (2009) investigated the role of social support from co-workers and supervisors on the stress satisfaction relationship. Their findings indicated that there were moderating influences of 
social support role from both co-workers and supervisors on the stress-satisfaction relationship. Workers with high level of social support interaction were more satisfied with their works than workers with less support.

The finding that social support moderates the relationship between work pressure and safety behavior safety participation, as well as the relationship between safety communication and safety participation, could be attributed to the fact that these factors are highly likely to be influenced by a worker's daily interactions with supervisors, co-workers and family, thereby reducing work-related pressure and increasing communication (Hsu, Lee, Wu, \& Takano, 2010; Lingard, Cooke, \& Blismas, 2009). Consequently, social support facilitates safety communication and reduces work-related pressure, which is of key importance to predicting construction workers' safety behavior (Wedgeworth, LaRocca, Chaplin, \& Scogin, 2016).

\subsection{Theoretical and Practical Implications}

This study specifically investigated construction workers' safety-related behavior by using organizational safety practices as the antecedents and social support as a moderator in the Saudi construction industry. The study contributes theoretically to the existing safety literature by addressing an important research gap that has not previously been investigated by studies concerning safety. First, this study has contributed significantly to the literature by introducing the role of social support as a moderating variable in the relationship between safety practices and foreign construction workers' safety behavior in Saudi Arabia. This model provides additional areas of study to safety researchers regarding the importance of social support in enhancing safety-related behavior. The research findings have provided new avenues for the safety literature by offering new information on the role of social support in this context. In this regard, social support is proved to be helpful to foreign workers because it has the ability to facilitate the foreign workers' safety behavior through social interactions.

This study has important practical implications for construction companies in Saudi Arabia because the results have significant implications for the field of construction safety, particularly in terms of enhancing foreign construction workers' safety related behaviors.

Since safety communication was empirically shown to predict workers' level of safety participation in this study, the management of the Al Muhaidib Company could improve foreign construction workers' level of safety participation through properly communicating safety practices to the workers. For example, always informing the workers about current safety concerns and issues on the construction site, as well as operating an open door policy regarding safety issues relevant to the company.

Finally, since social support was found to be an important moderator of the relationships between different facets of safety practices, as well as being a critical element in the promotion of foreign construction workers' safety behavior, it 
is recommended that the $\mathrm{Al}$ Muhaidib Company encourages supervisor support for foreign construction workers. For instance, the supervisors could assist the foreign construction workers when they are facing difficulties. Further, the supervisors could be encouraged to cooperate with the foreign construction workers in solving any such difficulties.

\subsection{Limitation and Recommendations for Future Research}

The present study has succeeded in providing various insights into the importance of safety practices, social support and safety behavior. Nevertheless, the study was subject to several notable limitations. Firstly, the study only focused on one company which is Al Muhaidib Construction Company it may therefore be difficult to generalise the findings to other construction companies in Saudi Arabia because the sampled workers came from a single construction company.

Secondly, in this study, the construction workers' safety-related behavior was measured using self-report measures that may be affected by social desirability bias (Grimm, 2010). There exists a possibility that the workers may have over-reported their behavior. However, in order to reduce the possibility of social desirability bias in this study, the researcher informed the respondents that their answers would be kept confidential and used solely for academic purposes. Therefore, the results should be used with caution.

\section{Conclusion}

Numerous literature gaps can be seen in the safety literature in terms of the relationships between organisational safety practices and safety behavior due to inconsistencies in prior findings (Christian, Bradley, Wallace, \& Burke, 2009; Zohar, 1980). Therefore, social support was introduced in this study because it had not been considered by earlier researchers. The present study contributed to the safety literature by responding to all the identified research objectives.

\section{Conflicts of Interest}

The author declares no conflicts of interest regarding the publication of this paper.

\section{References}

Abualrub, R. F., Omari, F. H., Al Rub, A. B. U., \& Fawzi, A. (2009). The Moderating Effect of Social Support on the Stress-Satisfaction Relationship among Jordanian Hospital Nurses. Journal of Nursing Management, 17, 870-878. https://doi.org/10.1111/j.1365-2834.2009.01007.x

Alasamri, H., Chrisp, M. T., \& Bowles, G. (2012). A Framework for Enhancing and Improving the Safety Culture on Saudi Construction Sites. Proceedings of the 28th Annual ARCOM Conference, Association of Researchers in Construction Management, Edinburgh, 3-5 September 2012, 475-485.

Al-Haadir, S., \& Panuwatwanich, K. (2011). Critical Success Factors for Safety Program Implementation among Construction Companies in Saudi Arabia. Procedia Engineer- 
ing, 14, 148-155. https://doi.org/10.1016/j.proeng.2011.07.017

Al-Haadir, S., Panuwatwanich, K., \& Stewart, R. (2013). Developing a Model of Construction Safety in Saudi Arabia. Proceedings of the 13th East Asia-Pacific Conference on Structural Engineering and Construction, Sapporo, 11-13 September 2013, F-3.

Al-Haadir, S., Panuwatwanich, K., \& Stewart, R. A. (2010). Empirical Analysis of the Impacts of Safety Motivation and Safety Climate on Safety Behaviour.

Ali, H., Azimah Chew Abdullah, N., \& Subramaniam, C. (2009). Management Practice in Safety Culture and Its Influence on Workplace Injury: An Industrial Study in Malaysia. Disaster Prevention and Management, 18, 470-477. https://doi.org/10.1108/09653560911003660

Ali, M., Aziz, S., Pham, T. N., Babalola, M. T., \& Usman, M. (2020). A Positive Human Health Perspective on How Spiritual Leadership Weaves Its Influence on Employee Safety Performance: The Role of Harmonious Safety Passion. Safety Science, 131, Article ID: 104923. https://doi.org/10.1016/j.ssci.2020.104923

Anderson, J. C., \& Gerbing, D. W. (1988). Structural Equation Modeling in Practice: A Review and Recommended Two-Step Approach. Psychological Bulletin, 103, 411-423. https://doi.org/10.1037/0033-2909.103.3.411

Arboleda, A., Morrow, P. C., Crum, M. R., \& Shelley, M. C. (2003). Management Practices as Antecedents of Safety Culture within the Trucking Industry: Similarities and Differences by Hierarchical Level. Journal of Safety Research, 34, 189-197. https://doi.org/10.1016/S0022-4375(02)00071-3

Barlow, L., \& Iverson, R. D. (2005). Workplace Safety. In J. Barling, E. Kevin Kelloway, \& M. R. Frone (Ed.), Handbook of Work Stress (pp. 247-265). Thousand Oaks, CA: SAGE Publications, Inc. https://doi.org/10.4135/9781412975995.n10

Bentley, T. A., \& Haslam, R. A. (2001). Identification of Risk Factors and Countermeasures for Slip, Trip and Fall Accidents during the Delivery of Mail. Applied Ergonomics, 32, 127-134. https://doi.org/10.1016/S0003-6870(00)00048-X

Berhan, E. (2020). Management Commitment and Its Impact on Occupational Health and Safety Improvement: A Case of Iron, Steel and Metal Manufacturing Industries. International Journal of Workplace Health Management, 13, 427-444. https://doi.org/10.1108/IJWHM-01-2019-0005

Borman, W. C., \& Motowidlo, S. M. (1993). Expanding the Criterion Domain to Include Elements of Contextual Performance (p. 71). Personnel Selection in Organizations, San Francisco, CA: Jossey-Bass.

Bosak, J., Coetsee, W. J., \& Cullinane, S. J. (2013). Safety Climate Dimensions as Predictors for Risk Behavior. Accident Analysis \& Prevention, 55, 256-264.

https://doi.org/10.1016/j.aap.2013.02.022

Brislin, R. W. (1970). Back-Translation for Cross-Cultural Research. Journal of Cross-Cultural Psychology, 1, 185-216. https://doi.org/10.1177/135910457000100301

Broadbent, D. G. (2004). Maximizing Safety Performance via Leaderships. 28th World Congress of Psychology, Beijing, August 2004, 11-14.

Bronkhorst, B. (2015). Behaving Safely under Pressure: The Effects of Job Demands, Resources, and Safety Climate on Employee Physical and Psychosocial Safety. Journal of Safety Research, 55, 63-72. https://doi.org/10.1016/j.jsr.2015.09.002

Christian, M. S., Bradley, J. C., Wallace, J. C., \& Burke, M. J. (2009). Workplace Safety: A Meta-Analysis of the Roles of Person and Situation Factors. Journal of Applied Psychology, 94, 1103-1127. https://doi.org/10.1037/a0016172

Cigularov, K. P., Chen, P. Y., \& Rosecrance, J. (2010). The Effects of Error Management 
Climate and Safety Communication on Safety: A Multi-Level Study. Accident Analysis \& Prevention, 42, 1498-1506. https://doi.org/10.1016/j.aap.2010.01.003

Conchie, S. M., Taylor, P. J., \& Charlton, A. (2011). Trust and Distrust in Safety Leader-Ship: Mirror Reflections? Safety Science, 49, 1208-1214. https://doi.org/10.1016/j.ssci.2011.04.002

Cox, S. J., \& Cheyne, A. J. T. (2000). Assessing Safety Culture in Offshore Environments. Safety Science, 34, 111-129. https://doi.org/10.1016/S0925-7535(00)00009-6

Demirkesen, S. (2020). Measuring Impact of Lean Implementation on Construction Safety Performance: A Structural Equation Model. Production Planning \& Control, 31, 412-433. https://doi.org/10.1080/09537287.2019.1675914

Faul, F., Erdfelder, E., Lang, A. G., \& Buchner, A. (2007). G* Power 3: A Flexible Statistical Power Analysis Program for the Social, Behavioral, and Biomedical Sciences. Research Methods, 39, 175-191. https://doi.org/10.3758/BF03193146

Fleming, M., \& Lardner, R. (1999). Safety Culture: The Way Forward. Chemical Engineer, $676,16-18$.

Foster, J., \& Nichols, S. B. (2015). The Mediating Effects of Behavior. In S. Clarke, T. M. Probst, F. Guldenmund, \& J. Passmore (Eds.), The Wiley Blackwell Handbook of the Psychology of Occupational Safety and Workplace Health (pp. 38-60). Hoboken, NJ: John Wiley \& Sons, Ltd.

Fujiwara, K., Tsukishima, E., Tsutsumi, A., Kawakami, N., \& Ishi, R. (2003). Interpersonal Conflict, Social Support, and Burnout among Home Care Workers in Japan. Journal of Occupational Health, 45, 313-320. https://doi.org/10.1539/joh.45.313

General Organization for Social Insurance (GOSI) (2012). Workplace Injury Statistics. http://www.gosi.gov.sa/portal/web/guest/opendata

Ghasemi, F., Kalatpour, O., Moghimbeigi, A., \& Mohhamadfam, I. (2017). A Path Analysis Model for Explaining Unsafe Behavior in Workplaces: The Effect of Perceived Work Pressure. International Journal of Occupational Safety and Ergonomics, 24, 303-310. https://doi.org/10.1080/10803548.2017.1313494

Glendon, A. I., \& Litherland, D. K. (2001). Safety Climate Factors, Group Differences and Safety Behavior in Road Construction. Safety Science, 39, 157-188. https://doi.org/10.1016/S0925-7535(01)00006-6

Glendon, A. I., \& Stanton, N. A. (2000). Perspectives on Safety Culture. Safety Science, 34, 193-214. https://doi.org/10.1016/S0925-7535(00)00013-8

Grimm, P. (2010). Social Desirability Bias. In J. Sheth, \& N. Malhotra (Eds.), Wiley International Encyclopedia of Marketing. Hoboken, NJ: John Wiley \& Sons. https://doi.org/10.1002/9781444316568.wiem02057

Haenlein, M., \& Kaplan, A. M. (2004). A Beginner's Guide to Partial Least Squares Analysis. Understanding Statistics, 3, 283-297. https://doi.org/10.1207/s15328031us0304 4

Hair, J. F., Ringle, C. M., \& Sarstedt, M. (2011). PLS-SEM: Indeed a Silver Bullet. Journal of Marketing Theory and Practice, 19, 139-152. https://doi.org/10.2753/MTP1069-6679190202

Hale, A. R., \& Hovden, J. (1998). Management and Culture: The Third Age of Safety. A Review of Approaches to Organizational Aspects of Safety, Health and Environment. In A. R. Hale, \& J. Hovden (Eds.), Occupational Injury: Risk, Prevention and Intervention (pp. 129-165). Boca Raton, FL: CRC Press.

Hardison, D., Behm, M., Hallowell, M. R., \& Fonooni, H. (2014). Identifying Construction Supervisor Competencies for Effective Site Safety. Safety Science, 65, 45-53. 
https://doi.org/10.1016/j.ssci.2013.12.013

Helm, S., Eggert, A., \& Garnefeld, I. (2010). Modeling the Impact of Corporate Reputation on Customer Satisfaction and Loyalty Using Partial Least Squares. In V. V., Esposito, W. Chin, J. Henseler, \& H. Wang (Ed.), Handbook of Partial Least Squares (pp. 515-534). Berlin, Heidelberg: Springer. https://doi.org/10.1007/978-3-540-32827-8 23

Henseler, J., Hubona, G., \& Ray. P. A. (2016). Using PLS Path Modeling in New Technology.

Henseler, J., Ringle, C. M., \& Sarstedt, M. (2015). A New Criterion for Assessing Discriminant Validity in Variance-Based Structural Equation Modeling. Journal of the Academy of Marketing Science, 43, 115-135. https://doi.org/10.1007/s11747-014-0403-8

Hobfoll, S. E., \& Stokes, J. P. (1988). The Process and Mechanics of Social Support. In S. Duck, D. F. Hay, S. E. Hobfoll, W. Ickes, \& B. M. Montgomery (Eds.), Handbook of Personal Relationships: Theory, Research and Interventions (pp. 497-517). Hoboken, NJ: John Wiley \& Sons.

Hofmann, D. A., \& Mark, B. (2006). An Investigation of the Relationship between Safety Climate and Medication Errors as Well as Other Nurse and Patient Outcomes. Personnel Psychology, 59, 847-869. https://doi.org/10.1111/j.1744-6570.2006.00056.x

Hofmann, D. A., \& Morgeson, F. P. (1999). Safety-Related as a Social Exchange: The Role of Perceived Organizational Support and Leader-Member Exchange. Journal of Applied Psychology, 84, 286-296. https://doi.org/10.1037/0021-9010.84.2.286

Hofmann, D. A., Morgeson, F. P., \& Gerras, S. J. (2003). Climate as a Moderator of the Relationship between Leader-Member Exchange and Content Specific Citizenship: Safety Climate as an Exemplar. Journal of Applied Psychology, 88, 170-178. https://doi.org/10.1037/0021-9010.88.1.170

Hon, C. K., Chan, A. P., \& Wong, F. K. (2010). An Analysis for the Causes of Accidents of Repair, Maintenance, Alteration and Addition Works in Hong Kong. Safety Science, 48, 894-901. https://doi.org/10.1016/j.ssci.2010.03.013

Hong, S. J. (2015). Perception of Safety Attitude and Priority and Progress of Safe Practices of Nurses in Emergency Room. Advanced Science and Technology Letters, 104, 156-163.

Hsu, S. H., Lee, C. C., Wu, M. C., \& Takano, K. (2010). The Influence of Organizational Factors on Safety in Taiwanese High-Risk Industries. Journal of Loss Prevention in the Process Industries, 23, 646-653. https://doi.org/10.1016/j.jlp.2010.06.018

Inness, M., Turner, N., Barling, J., \& Stride, C. B. (2010). Transformational Leadership and Employee Safety Performance: A Within-Person, Between-Jobs Design. Journal of Occupational Health Psychology, 15, 279-290. https://doi.org/10.1037/a0019380

International Labour Organization (ILO) (2012). World of Work Report. Geneva: International Labour Office.

Jamal, M. (2013). Job Stress among Hospital Employees in Middle East : Social Support and Type A Behavior as Moderators. Middle East Journal of Business, 8, 7-16.

Jiang, L., Yu, G., Li, Y., \& Li, F. (2010). Perceived Colleagues' Safety Knowledge/Behavior and Safety Performance: Safety Climate as a Moderator in a Multilevel Study. Accident Analysis \& Prevention, 42, 1468-1476. https://doi.org/10.1016/j.aap.2009.08.017

Katz-Navon, T. A. L., Naveh, E., \& Stern, Z. (2005). Safety Climate in Health Care Organizations: A Multidimensional Approach. Academy of Management Journal, 48, 1075-1089. https://doi.org/10.5465/amj.2005.19573110 
Keffane, S., \& Delhomme, P. (2013). Assessing the Mediating Role of Communication in Safety Management and Performance for Road Safety Practices: French Organizations Model. Proceedings Book, 26.

Krejcie, R. V., \& Morgan, D. W. (1970). Determining Sample Size for Research Activities. Educational and Psychological Measurement, 30, 607-610. https://doi.org/10.1177/001316447003000308

Lee, C. Y., \& Hong, K. S. (2005). Work-Family Conflict and Its Relationship with Social Support: A Study at Private Educational Institutions in Kuching, Sarawak, Malaysia. Educational Research Journal, 20, 221-243.

Leung, M. Y., Liang, Q., \& Olomolaiye, P. (2015). Impact of Job Stressors and Stress on the Safety Behavior and Accidents of Construction Workers. Journal of Management in Engineering, 32, Article ID: 04015019.

Lingard, H. C., Cooke, T., \& Blismas, N. (2009). Group-Level Safety Climate in the Australian Construction Industry: Within-Group Homogeneity and Between-Group Differences in Road Construction and Maintenance. Construction Management and Economics, 27, 419-432. https://doi.org/10.1080/01446190902822971

Liu, M., \& Liao, P. C. (2019). Integration of Hazard Rectification Efficiency in Safety Assessment for Proactive Management. Accident Analysis \& Prevention, 129, 299-308. https://doi.org/10.1016/j.aap.2019.05.020

Liu, M., Tang, P., Liao, P. C., \& Xu, L. (2020). Propagation Mechanics from Workplace Hazards to Human Errors with Dissipative Structure Theory. Safety Science, 126, Article ID: 104661. https://doi.org/10.1016/j.ssci.2020.104661

Liu, S., Yang, X., \& Mei, Q. (2020). The Effect of Perceived Organizational Support for Safety and Organizational Commitment on Employee Safety: A Meta-Analysis. International Journal of Occupational Safety and Ergonomics, 1-12.

Lu, C. S., \& Yang, C. S. (2011). Safety Climate and Safety in the Passenger Ferry Context. Accident Analysis \& Prevention, 43, 329-341. https://doi.org/10.1016/j.aap.2010.09.001

Martz, E., Bodner, T., \& Livneh, H. (2010). Social Support and Coping as Moderators of Perceived Disability and Posttraumatic Stress Levels among Vietnam Theater Veterans. Health, 2, 332-341. https://doi.org/10.4236/health.2010.24050

Mearns, K., Whitaker, S. M., \& Flin, R. (2003). Safety Climate, Safety Management Practice and Safety Performance in Offshore Environments. Safety Science, 41, 641-680. https://doi.org/10.1016/S0925-7535(02)00011-5

Ministry of Economy and Planning (MEP) (2014). The Economic Indicators. http://www.mep.gov.sa/en/economic-indicators/

Ministry of Labour and Social Development (MLSD) (2013). http://sd.mlsd.gov.sa

Ministry of Labour and Social Development (MLSD) (2016). Rules and regulations. http://sd.mlsd.gov.sa/ar/policies

Mohamed, S. (2002). Safety Climate in Construction Site Environments. Journal of Construction Engineering and Management, 128, 375-384. https://doi.org/10.1061/(ASCE)0733-9364(2002)128:5(375)

Naveh, E., Katz-Navon, T., \& Stern, Z. (2006). Readiness to Report Medical Treatment Errors: The Effects of Safety Procedures, Safety Information, and Priority of Safety. Medical Care, 44, 117-123. https://doi.org/10.1097/01.mlr.0000197035.12311.88

Neal, A., \& Griffin, M. A. (2006). A Study of the Lagged Relationships among Safety Climate, Safety Motivation, Safety, and Accidents at the Individual and Group Levels. Journal of Applied Psychology, 91, 946-953. https://doi.org/10.1037/0021-9010.91.4.946 
Neal, A., Griffin, M. A., \& Hart, P. M. (2000). The Impact of Organizational Climate on Safety Climate and Individual. Safety Science, 34, 99-109. https://doi.org/10.1016/S0925-7535(00)00008-4

Occupational Safety \& Health Administration. (2015). Business Case for Safety and Health. https://www.osha.gov/dcsp/products/topics/businesscase/costs.html

Podsakoff, P. M., MacKenzie, S. B., Lee, J. Y., \& Podsakoff, N. P. (2003). Common Method Biases in Research: A Critical Review of the Literature and Recommended Remedies. Journal of Applied Psychology, 88, 879-903. https://doi.org/10.1037/0021-9010.88.5.879

Pordanjani, T. R., \& Ebrahimi, A. M. (2015). Safety Motivation and Work Pressure as Predictors of Occupational Accidents in the Petrochemical Industry. Health Scope, 4, e26492. https://dx.doi.org/10.17795/jhealthscope-26492

Rautiainen, R. H. (2012). Factors Affecting Occupational Safety and Health of Foreign Farm Workers in Nordic Countries. Copenhagen: Nordic Council of Ministers.

Ringle, C. M., Wende, S., \& Becker, J. M. (2015). SmartPLS 3. Boenningstedt: SmartPLS GmbH. http://www.smartpls.com

Rundmo, T., \& Moen, B. E. (2007). Risk Sensitivity and Priority of Safety. Risk, Reliability and Societal Safety, 2, 1623-1629.

Sadullah, Ö., \& Kanten, S. (2009). A Research on the Effect of Organizational Safety Climate upon the Safe S. Ege Academic Review, 9, 923-932.

Sekaran, U., \& Bougie, R. (2003). Research Methods for Business, a Skill Building Approach. New York, NY: John Willey \& Sons. Inc.

Seo, D. C. (2005). An Explicative Model of Unsafe Work Behavior. Safety Science, 43, 187-211. https://doi.org/10.1016/j.ssci.2005.05.001

Shi, H. (2020). The Influence of Safety-Specific Transformational Leadership and High-Quality Relationships on Mindful Safety Practices through Safety Climate: A Study in Chinese Petroleum Industry. Journal of Applied Security Research, 1-17. https://doi.org/10.1080/19361610.2020.1761744

Usukhbayar, R., \& Choi, J. (2020). Critical Safety Factors Influencing on the Safety Performance of Construction Projects in Mongolia. Journal of Asian Architecture and Building Engineering, 19, 600-612.

Vinodkumar, M. N., \& Bhasi, M. (2009). Safety Climate Factors and Its Relationship with Accidents and Personal Attributes in the Chemical Industry. Safety Science, 47, 659-667. https://doi.org/10.1016/j.ssci.2008.09.004

Vinodkumar, M. N., \& Bhasi, M. (2010). Safety Management Practices and Safety Behavior: Assessing the Mediating Role of Safety Knowledge and Motivation. Accident Analysis \& Prevention, 42, 2082-2093. https://doi.org/10.1016/j.aap.2010.06.021

Vredenburgh, A. G. (2002). Organizational Safety: Which Management Practices Are Most Effective in Reducing Employee Injury Rates? Journal of Safety Research, 33, 259-276.

Wedgeworth, M., LaRocca, M. A., Chaplin, W. F., \& Scogin, F. (2016). The Role of Interpersonal Sensitivity, Social Support, and Quality of Life in Rural Older Adults. Geriatric Nursing, 38, 22-26. https://doi.org/10.1016/j.gerinurse.2016.07.001

Wickramasinghe, V. (2012). Supervisor Support as a Moderator between Work Schedule Flexibility and Job Stress: Some Empirical Evidence from Sri Lanka. International Journal of Workplace Health Management, 5, 44-55.

https://doi.org/10.1108/17538351211215384 
Xia, N., Xie, Q., Griffin, M. A., Ye, G., \& Yuan, J. (2020). Antecedents of Safety in Construction: A Literature Review and an Integrated Conceptual Framework. Accident Analysis \& Prevention, 148, Article ID: 105834.

https://doi.org/10.1016/j.aap.2020.105834

Zohar, D. (1980). Safety Climate in Industrial Organizations: Theoretical and Applied Implications. Journal of Applied Psychology, 65, 96-102.

https://doi.org/10.1037/0021-9010.65.1.96

Zohar, D., \& Erev, I. (2007). On the Difficulty of Promoting Workers' Safety Behavior: Overcoming the Underweighting of Routine Risks. International Journal of Risk Assessment \& Measurement, 7, 122-136. https://doi.org/10.1504/IJRAM.2007.011726 